\title{
Small pulmonary arteries in some natives of La Paz, Bolivia
}

\author{
D HEATH, P SMITH, J RIOS DALENZ, D WILliamS, P HARRIS
}

From the Department of Pathology, University of Liverpool, Section of Anatomical Pathology, Hospital No 1, Caja Nacional de Seguridad Social, La Paz, Bolivia, and The Cardiothoracic Institute, University of London

ABSTRACT A histological study was made of the small pulmonary blood vessels in pieces of lung obtained at necropsy from 19 long-term residents of La Paz, Bolivia $(3800 \mathrm{~m})$. There was variation in the response of the pulmonary vasculature of these subjects to the chronic hypoxia of high altitude. The most characteristic finding, seen in seven of the 16 cases beyond infancy, was distal extension of vascular smooth muscle into pulmonary arterioles as small as $20 \mu \mathrm{m}$ in diameter. Medial hypertrophy of the muscular pulmonary arteries occurred in only three of these seven subjects. Intimal fibrosis was seen in eight of the 19 cases and was ascribed to age; such fibrotic proliferation may affect the reversibility of hypoxic pulmonary hypertension and associated vascular changes in highlanders.

During a recent expedition to the Andes we spent some time in La Paz, the capital city of Bolivia, which is situated at high altitude lying beneath the mountain Illimani $(6450 \mathrm{~m})$. There is considerable variation in the altitude of different parts of the city for it slopes steeply downwards from its airport to residential areas in the lower valleys. Its airport is the highest in the world and is situated on the Altiplano at an altitude exceeding $4000 \mathrm{~m}$. The figure usually taken as the average elevation of this hilly city is $3800 \mathrm{~m}$. La Paz has a population of 650000 and several large hospitals and thus offers an unusual opportunity to study from necropsy specimens of lung the normal pulmonary vasculature of the native highlander exposed all his life to the hypoxia of high altitude. In contrast, on previous expeditions, we have found it virtually impossible to acquire specimens of human lung from the small communities of Quechua Indians who populate the Peruvian Andes. We were fortunate enough to obtain necropsy specimens of lung from 19 residents of $\mathrm{La} \mathrm{Paz}$ who had no disease of heart and lungs and who died from some disease unrelated to the chest. We present our findings in this paper.

\section{Cases studied}

We were able to obtain necropsy specimens of lung from 19 cases. The age, sex, race, and cause of death

Address for reprint requests: Professor D Heath, Department of Pathology, University of Liverpool, Liverpool. of each case is shown in table 1 .While we were able to exclude all cases with cardiopulmonary disease, that might in itself have induced changes in the pulmonary vasculature, it was also advisable to establish wherever possible the birthplace and place of residence of the cases studied. Not everyone dying at high altitude is a native highlander. We were able to establish unequivocally the birthplace and its altitude, and the duration of residence in $\mathrm{La} \mathrm{Paz}$ in 12 of the 19 cases (table 2). The other seven subjects were stated on the hospital notes to be permanent resi-

Table 1 Age, sex, race, and cause of death

\begin{tabular}{|c|c|c|c|c|}
\hline $\begin{array}{l}\text { Case } \\
\text { no }\end{array}$ & $\begin{array}{l}\text { Age } \\
(y r)^{*}\end{array}$ & $\operatorname{Sex}$ & Race & Cause of death \\
\hline 1 & $1 \mathrm{mo}$ & $\mathrm{F}$ & C & Bronchopneumonia \\
\hline 2 & 1 & $\mathbf{M}$ & $\mathbf{M}$ & Viral meningoencephalitis \\
\hline 3 & 1 & $\mathbf{F}$ & $\mathrm{C}$ & Bacterial meningitis \\
\hline 4 & 3 & $\mathbf{F}$ & I & Postoperative death after hip surgery \\
\hline 5 & 20 & $\mathbf{M}$ & $\mathbf{C}$ & Ruptured liver with haemoperitoneum \\
\hline 6 & 33 & $\mathbf{F}$ & $\mathbf{I}$ & Peritonitis. Necrotising enteritis \\
\hline 7 & 34 & $\mathbf{F}$ & $\mathbf{M}$ & Septic abortion \\
\hline 8 & 35 & $\mathbf{M}$ & I & Ruptured liver with haemoperitoneum \\
\hline 9 & 45 & $\mathbf{F}$ & C & Peritonitis. Enteritis \\
\hline 10 & 49 & $\mathbf{F}$ & C & $\begin{array}{l}\text { Subarachnoid haemorrhage. Berry } \\
\text { aneurysm }\end{array}$ \\
\hline 11 & 60 & $\mathbf{M}$ & $\mathbf{M}$ & Carcinoma of gall bladder \\
\hline 12 & 60 & $\mathbf{F}$ & $\mathrm{C}$ & Lymphocytic lymphoma \\
\hline 13 & 70 & $\mathbf{M}$ & I & Haemothorax from trauma \\
\hline 14 & 70 & $\mathbf{M}$ & I & Tuberculous peritonitis. Leishmaniasis \\
\hline 15 & 70 & $\mathbf{M}$ & $\mathbf{I}$ & Cirrhosis of the liver \\
\hline 16 & 72 & $\mathbf{M}$ & $\mathbf{M}$ & Peritonitis. Ischiorectal abscess \\
\hline 17 & 73 & $\mathbf{M}$ & $\mathrm{C}$ & Chronic glomerulonephritis \\
\hline 18 & 80 & $\mathbf{F}$ & I & Carcinoma of gall bladder \\
\hline 19 & 83 & $\mathbf{M}$ & $\mathbf{M}$ & Amoebic colitis \\
\hline
\end{tabular}

* Except case 1 .

$\mathrm{C}=$ Caucasian, $\mathbf{I}=$ Indian, $\mathbf{M}=\mathbf{M e s t i z o}$ 
Table 2 Birthplace, its altitude, and duration of residence in La Paz in 12 of the cases studied

\begin{tabular}{llll}
\hline $\begin{array}{l}\text { Case } \\
\text { no }\end{array}$ & Birthplace & Altitude in $m$ & $\begin{array}{l}\text { Number of years } \\
\text { residence in La Paz }(\text { or } \\
\text { Oruro where specified })\end{array}$ \\
\hline 1 & La Paz & 3800 & Whole of life \\
2 & La Paz & 3800 & Whole of life \\
5 & La Paz & 3800 & Whole of life \\
7 & Oruro & 3800 & Oruro 30 \\
9 & Sorata & 2800 & Many \\
10 & Reyes & 150 & 29 \\
11 & Viacha & 4100 & Many \\
14 & Unknown & - & Many \\
15 & La Paz & 3800 & Whole of life \\
17 & Oruro & 3800 & Oruro. Whole of life \\
18 & Guaqui & 4000 & Many \\
19 & Tiquina & 4000 & 50 \\
\hline
\end{tabular}

dents of La Paz but we were unable to confirm this personally.

\section{Method}

The lung available for histological examination had been taken at necropsy for routine microscopic study. Paraffin sections, $5 \mu \mathrm{m}$ in thickness, were cut and stained with haematoxylin and eosin and by Miller's technique for elastic tissue with a Van Gieson counterstain. The pulmonary blood vessels studied were categorised into "muscular pulmonary arteries" and "pulmonary arterioles" according to the classification of Brenner. ${ }^{1}$ However, in accord with the growing realisation that even in sea-level subjects smooth muscle extends more peripherally in the pulmonary vasculature than envisaged by Brenner,

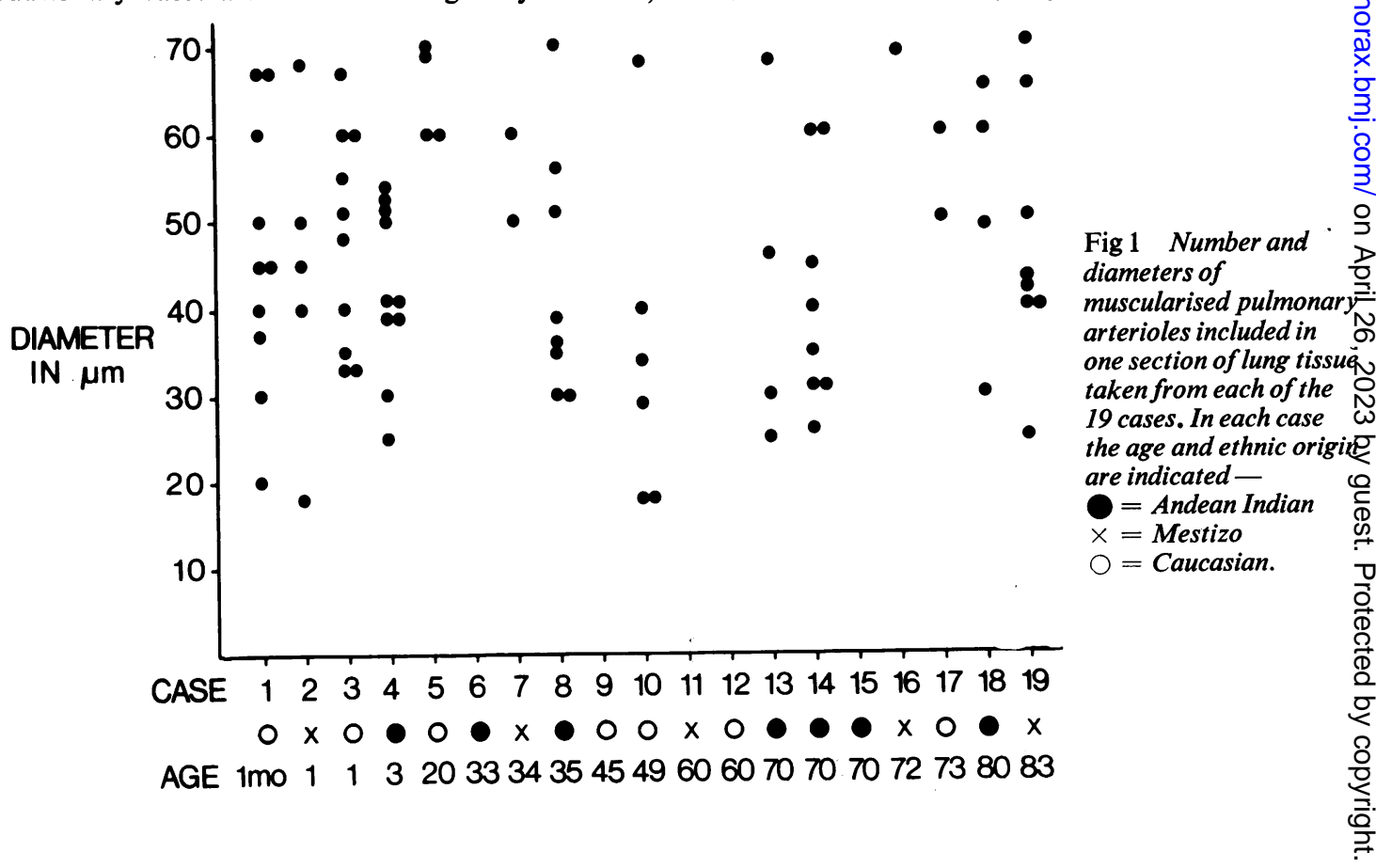

we modified slightly the range of diameters of pulmonary arterial vessels falling in these categories. 듬 Thus we defined "muscular pulmonary arteries" as $\overline{\bar{\sigma}}$ arterial vessels in the lung with an external diameter $\mathbb{\Phi}$ exceeding $70 \mu \mathrm{m}$ and usually lying adjacent to terminal bronchioles. "Pulmonary arterioles" were $e^{\infty}$ arterial vessels in the lung less than $70 \mu \mathrm{m}$ in dia- $\vec{\circ}$ meter. At sea level pulmonary arterioles have a wall $\overrightarrow{\vec{\omega}}$ consisting of a single elastic lamina and they are ${ }^{\omega}$ situated adjacent to alveolar ducts and sacs. "Muscu- $\overrightarrow{2}$ larised pulmonary arterioles" were less than $70 \mu \mathrm{m}$ in diameter but had a distinct media of circularo smooth muscle sandwiched between inner and outer ${ }_{0}^{\infty}$ elastic laminae.

Measurements were made of the thickness of theo media and of the layer of intimal fibrosis in the muscular pulmonary arteries. Data were obtained $\supset$ only from vessels that had been sectioned as near asc possible transversely. In each instance the diameteres was taken as the mean of two measurements, at right $\overrightarrow{ }$ angles to each other, of the distance between dia- $\infty$ metrically opposite points on the external elastic lamina. The medial thickness was estimated as the mean of four measurements taken at points approximately equally spaced around the vessel wall. Fromo these data the thickness of the media was expressedo as a percentage of the external diameter.

The average thickness of intimal fibrous or fibro- $\overrightarrow{\vec{a}}$ elastic tissue, derived from four measurements $\exists$ obtained at points equally spaced around the lumen? of the vessel, was expressed as a percentage of the internal diameter of the vessel. This diameter was 
taken as the mean of two measurements, at right angles to each other, of the distance between diametrically opposite points on the internal elastic lamina.

The number and diameters of muscularised pulmonary arterioles included in one section of lung tissue from each case was determined (fig 1).

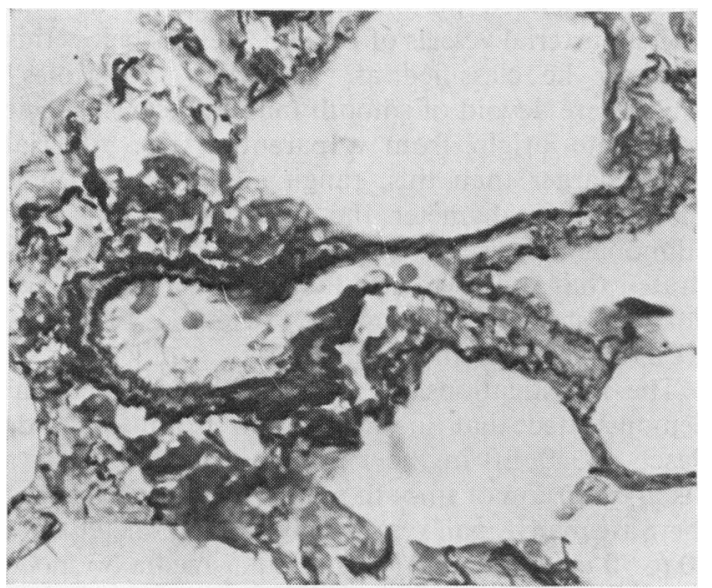

Fig 2 Transverse section of a muscularised pulmonary arteriole from a male Aymara Indian aged 35 years (case 8). Although this vessel measures only $75 \times 45 \mu \mathrm{m}$ it has a distinct media of circularly-orientated smooth muscle between inner and outer elastic laminae. This figure illustrates the remarkable degree of peripheral extension of smooth muscle in the pulmonary vasculature of some native highlanders. Two non-muscular branches of the arteriole, seen to the right, enter the capillary bed of the alveolar walls. Elastic Van Gieson, original magnification $\times 435$.

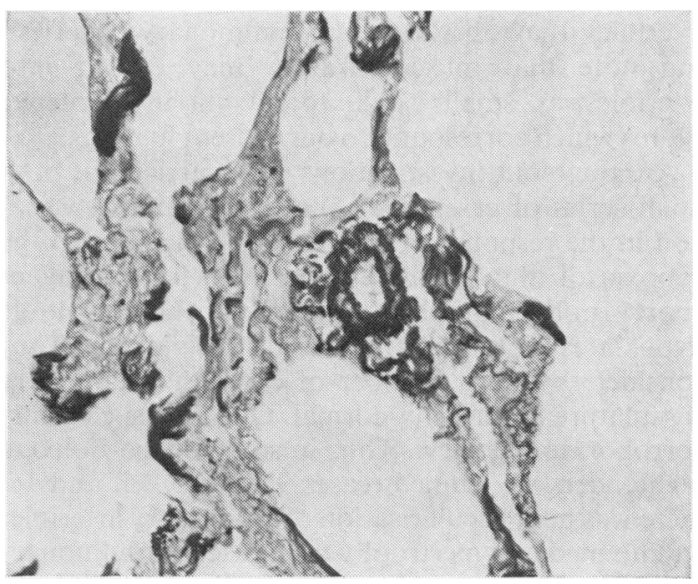

Fig 3 Transverse section of an even smaller muscularised pulmonary arteriole from the same case. This vessel measures only $40 \times 24 \mu \mathrm{m}$ but has a thick, well-defined muscular media. Elastic Van Gieson, original magnification $\times 375$.

\section{Results}

Muscularised pulmonary arterioles, as defined above, were found in all three infants and were prominent in seven of the 16 cases beyond infancy (cases $4,8,10$, $13,14,18$, and 19) (fig 1). They appeared as very small pulmonary arterial vessels with a distinct media of circularly-orientated smooth muscle sandwiched between inner and outer elastic laminae (figs 2, 3). In most of these cases muscularised pulmonary arterioles as small as $30 \mu \mathrm{m}$ in diameter were found and in one instance (case 10) smooth muscle extended peripherally in arterioles of only $20 \mu \mathrm{m}$ in diameter. In five cases (cases $6,9,11,12$, and 15 ) no muscularised pulmonary arterioles were found and in the remaining two (cases 16 and 17) the muscularised vessels found only just came into the category.

Observations on "muscular pulmonary arteries" are shown in table 3. Medial hypertrophy, defined as a medial thickness exceeding $7 \%$ of the external diameter, was found in only four cases (cases 1, 8, 14, and 19). In most cases the media of the "muscular pulmonary artcries" was thin and in some subjects (case 6) these normal looking vessels gave rise to non-muscularised pulmonary arterioles (fig 4).

Intimal fibrosis or fibroelastosis occurred in eight of the 19 cases (table 3) and was thought to be consistent with age change. It was usually slight in amount and only in case 19 , occurring in a man of 83 years, did it exceed a value of $10 \%$ of the internal diameter (fig 5). Longitudinal muscle was found in the intima in only one instance (case 14) and this subject showed both medial hypertrophy of muscular

Table 3 Percentage medial thickness and intimal fibrosis in muscular pulmonary arteries

\begin{tabular}{llll}
\hline $\begin{array}{l}\text { Case } \\
\text { no }\end{array}$ & $\begin{array}{l}\text { Noof } \\
\text { pulmonary } \\
\text { arteries } \\
\text { studied }\end{array}$ & $\begin{array}{l}\text { \% medial } \\
\text { thickness }\end{array}$ & $\begin{array}{l}\text { \% intimal } \\
\text { fibrosis }\end{array}$ \\
\hline 1 & 15 & $12 \cdot 4$ & \\
2 & 9 & $4 \cdot 1$ & 0 \\
3 & 15 & $5 \cdot 6$ & 0 \\
4 & 15 & $4 \cdot 6$ & 0 \\
5 & 20 & $5 \cdot 9$ & 0 \\
6 & 11 & $3 \cdot 6$ & 0 \\
7 & 12 & $3 \cdot 3$ & 0 \\
8 & 13 & $8 \cdot 0$ & 0 \\
9 & 8 & $2 \cdot 5$ & 0 \\
10 & 7 & $3 \cdot 9$ & 0 \\
11 & 10 & $4 \cdot 0$ & $1 \cdot 4$ \\
12 & 11 & $4 \cdot 1$ & 0 \\
13 & 14 & $5 \cdot 6$ & $4 \cdot 6$ \\
14 & 12 & $9 \cdot 2$ & $2 \cdot 3$ \\
15 & 9 & $5 \cdot 3$ & $5 \cdot 9$ \\
16 & 8 & $4 \cdot 9$ & 0 \\
17 & 11 & $4 \cdot 6$ & $3 \cdot 6$ \\
18 & 13 & $6 \cdot 3$ & $4 \cdot 3$ \\
19 & 14 & $7 \cdot 7$ & $4 \cdot 5$ \\
\hline
\end{tabular}




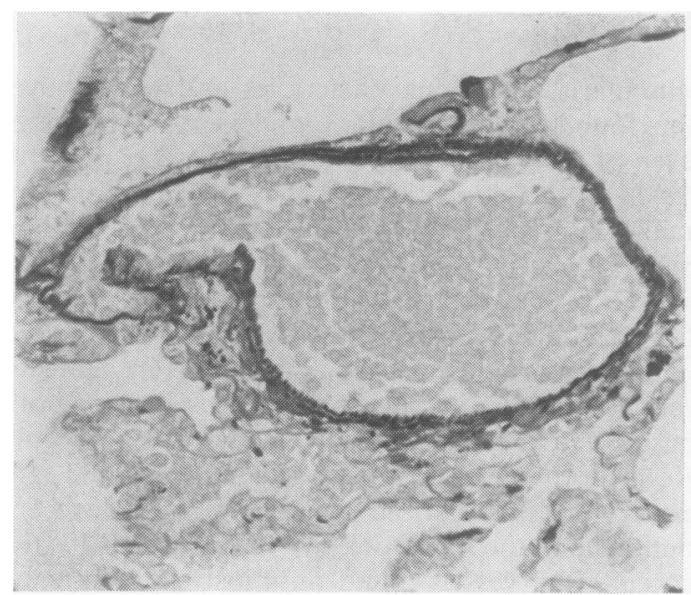

Fig 4 Transverse section of a "muscular pulmonary artery", $130 \times 90 \mu \mathrm{m}$, from an Aymara Indian woman of 33 years (case 6). Although this woman was a life-long resident of La Paz $(3800 \mathrm{~m})$ like the male Indian illustrated in fig 1, she has a thin-walled pulmonary vasculature in sharp contrast to the muscularisation shown by her fellow citizen. An arteriolar branch without muscle in its wall opens to the left. Elastic Van Gieson, original magnification $\times 397$.

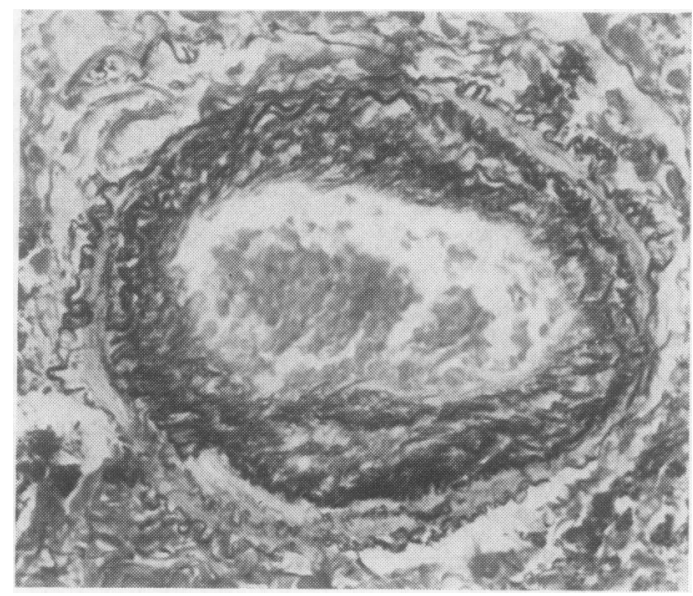

Fig 5 Transverse section of a "muscular pulmonary artery" from a male Aymara Indian aged 83 years (case 19). There is slight medial hypertrophy and severe intimal fibroelastosis interpreted as age-change. Elastic VanGieson, original magnification $\times 397$.

pulmonaryarteries and muscularisation of pulmonary arterioles. Intimal fibrosis was found in the pulmonary veins and venules in the same eight cases.

\section{Discussion}

Our study suggests that a significant feature of the pulmonary vasculature of the native highlander is $\stackrel{\text { की }}{\circ}$ the distal extension of smooth muscle into blood $\frac{C}{0}$ vessels of such small diameter as would lead them to $\overline{\bar{D}}$ be classed as pulmonary aterioles in the lowlander. $\widehat{\Phi}$ The classic papers of Brenner ${ }^{1}$ on the structure of the normal human pulmonary vasculature described the ${ }^{\text {s }}$ situation at sea level. He believed that smooth $\vec{O}$ muscle extended peripherally only as far as pul- $\overrightarrow{-}$ monary arterial vessels of $100 \mu \mathrm{m}$. Vessels below this $\omega_{\sigma}$ diameter he classified as "pulmonary arterioles" which were devoid of smooth muscle except at their immediate origin from a parent artery. Arterial vessels larger than this, ranging between 100 and 0 $1000 \mu \mathrm{m}$ in diameter, he designated "muscular 8 pulmonary arteries". Later studies have demon-응 strated that spirally orientated smooth muscle may not be lost finally in pulmonary arterioles until they $\vec{D}$ are as small as $70 \mu \mathrm{m}$ in diameter. ${ }^{2}$

The investigations of Arias-Stella and Saldaña ${ }^{3} \frac{\mathscr{C}}{\omega}$ demonstrated that in highlanders from Cerro de $\stackrel{+}{+}$ Pasco $(4330 \mathrm{~m})$ in the Peruvian Andes there is $\mathrm{a}_{\infty}^{\odot}$ distal extension of smooth muscle in the lung so that ${ }^{-}$ there are many small vessels ranging in diameter from 20 to $70 \mu \mathrm{m}$ with a distinct muscular media bounded by inner and outer elastic laminae lying adjacent to alveolar ducts and sacs. This led them to conclude ֶ that the pulmonary hypertension characteristic of $\stackrel{\mathbb{D}}{\varrho}$ healthy adults and children at high altitude ${ }^{4}$ has an $\overrightarrow{\vec{O}}$ organic basis in muscularisation of the distal portions $\frac{3}{3}$ of the pulmonary arterial tree. Our present findings in citizens of $\mathrm{La} \mathrm{Paz}(3800 \mathrm{~m})$ confirmed mus-? cularisation of the pulmonary arterioles in 10 of the 19 cases we examined including seven of the 16 으 beyond infancy. The Wagenvoorts ${ }^{2}$ agree that the $\underset{x}{\stackrel{D}{x}}$ response to hypoxia is stronger in pulmonary arterioles than in "muscular pulmonary arteries" and note that muscularisation may extend intoo arterioles as small as 20 to $30 \mu \mathrm{m}$ in diameter, $₹$ figures which correspond to our present findings. 을

Although our investigations were carried out on a $>$ small series of cases, they show considerable varia-을 tion in the response of the citizens of $\mathrm{La} \mathrm{Paz}$ to the hypoxia of high altitude. Wagenvoort and Wagenvoort ${ }^{2}$ note that the response to high altitude ${ }_{0}$ hypoxia is not the same in all individuals. They consider that in a number of cases the pulmonaryo vasculature is perfectly normal. Our results certainlyo corroborate this view. Thus in some of the Bolivian ${ }_{\mathbb{D}}$ highlanders we studied (cases $9,11,12,15$, and 16) $\stackrel{\mathcal{D}}{+}$ there was no muscularisation of pulmonary arterioles 0 and no medial hypertrophy of "muscular pulmonary arteries". The paper by Arias-Stella and Saldaña ${ }^{3} \stackrel{\Phi}{\stackrel{\Phi}{\perp}}$ has often been interpreted as indicating that mus- $\mathbb{\mathbb { Q }}$ cularisation of the distal portions of the pulmonary arterial tree is constant in the highlander and this may be because these Peruvian workers studied응 necropsy material collected at Cerro de Pasco 
$(4330 \mathrm{~m})$, a mining town on the Altiplano where the population is composed predominantly of Quechua Indians. In contrast our investigations were carried out on necropsy material derived from citizens of La Paz $(3800 \mathrm{~m})$ which includes Caucasians and Mestizos as well as Quechua and Aymara Indians.

The variation in response to hypoxia may be individual but it is conceivable that in part it may be racial. Thus in subjects beyond infancy we found abnormal muscularisation of pulmonary arterioles in five of seven Indians (cases 4, 8, 13, 14, and 18) in one of four Mestizos (case 19), and in one of five Caucasians (case 10). Such findings suggest that further investigations are required to ascertain if ethnic considerations are of importance in determining the reaction of the pulmonary vasculature to the chronic hypoxia of high altitude.

Only four of the cases that we studied showed medial hypertrophy of the "muscular pulmonary arteries" (cases 1, 8, 14, and 19). The first of these may be discounted as it occurred in an infant of one month which may be regarded as showing the physiological pulmonary hypertension of the neonatal period. The remaining three cases occurred in two adult Indians and one adult Mestizo. Wagenvoort and Wagenvoort ${ }^{2}$ describe and illustrate medial hypertrophy of a muscular pulmonary artery in a 21-year-old man native to an altitude of $3300 \mathrm{~m}$. The remaining four cases in the present series with muscularisation of the pulmonary arterioles (cases 4, 10,13 , and 18) showed no such medial hypertrophy of muscular pulmonary arteries.

One of the characteristic histological features of hypoxic hypertensive pulmonary vascular disease complicating emphysema is the development of longitudinal muscle in the intima of pulmonary arteries. ${ }^{56}$ It seems likely that intimal longitudinal muscle is derived from myofibroblasts which come to line the pulmonary arteries as an age change and which can be stimulated by arterial pulsation to form unequivocal intimal smooth muscle in the pulmonary arteries. ${ }^{7}$ Such intimal development of longitudinal muscle appears to become exaggerated by emphysema where the abnormal air spaces lead to distortion around them of the pulmonary arteries which, therefore, become subjected to longitudinal stretch. Since these physical factors appear to be of more importance than hypoxia in inducing intimal longitudinal muscle it is not surprising that this histological change is not nearly so characteristic of the pulmonary vasculature of the highlander as it is for pulmonary emphysema. Indeed in the present series intimal longitudinal muscle was found in only one subject (case 14).

Intimal fibrosis of the muscular pulmonary arteries was found in eight of the 19 cases and was clearly related to age, the change being seen only in those subjects in middle age or older. This age-change was mild and no more and no less severe than that seen at sea level. Intimal fibrosis is not a significant association of the muscularisation of the pulmonary vasculature found in the highlander or in other states of chronic hypoxia. Overt fibrous occlusion does not occur in the pulmonary arteries of highlanders but even slight intimal fibrosis might impair the reversibility of hypoxic pulmonary hypertension and the associated vascular muscularisation in the lung. First, it could interfere with the immediate reversibility of pulmonary hypertension thought to be caused by relief of hypoxic pulmonary vasoconstriction. Second, it could also hinder the long-term reversal of the elevated pulmonary arterial pressure thought to be associated with gradual regression of the arteriolar smooth muscle of highlanders over a period of two years. ${ }^{4}$ Certainly the fibrotic pulmonary artery of the mature or elderly highlander is different from the merely muscularised pulmonary arteriole of the rat kept in a decompression chamber which allows such rapid reversal of hypoxic pulmonary hypertension and associated right ventricular hypertrophy. ${ }^{89}$ This is yet another example of the principle that brief exposure to simulated high altitude for a period in a hypobaric chamber is not synonymous with life at natural high altitude. ${ }^{10}$

It has been suggested that the pulmonary veins are abnormal in highlanders. Wagenvoort and Wagenvoort ${ }^{2}$ found prominent thickening of the venous media leading to what they term "arterialisation" of the pulmonary veins in five of 14 individuals from altitudes exceeding $3000 \mathrm{~m}$. In seven of these subjects there was more than average intimal fibrosis of pulmonary veins and venules. In two people longitudinal muscle was found to have developed in the venous intima. We did not find changes ascribable to the hypoxia of high altitude in the pulmonary veins of the cases we studied.

This research work was supported by a grant from the British Heart Foundation. The expedition to the Bolivian Andes was made possible by a grant from the Wellcome Trust.

\section{References}

1 Brenner O. Pathology of the vessels of the pulmonary circulation. Arch Intern Med 1935;56:211, 457, 724, 976 1189.

2 Wagenvoort CA, Wagenvoort N. Pathology of pulmonary hypertension. New York: John Wiley and Sons, 1977.

3 Arias-Stella J, Saldaña $M$. The terminal portion of the pulmonary arterial tree in people native to high altitudes. Circulation 1963;28:915-25.

4 Peñaloza D, Sime F, Banchero N, Gamboa R. Pulmonary hypertension in healthy man born and living at high altitudes. Med Thorac 1962;19:449-60. 
5 Hicken P, Heath D, Brewer DB, Whitaker W. The small pulmonary arteries in emphysema. $J$ Pathol Bacteriol 1965;90:107-14.

6 Hasleton PS, Heath D, Brewer DB. Hypertensive pulmonary vascular disease in states of chronic hypoxia. $J$ Pathol Bacteriol 1968 ;95:431-40.

${ }^{7}$ Smith P, Heath D. The ultrastructure of age-associated intimal fibrosis in pulmonary blood vessels. $J$ Pathol 1980;130:247-53.

8 Abraham AS, Kay JM, Cole RB, Pincock AC. Haemo- dynamic and pathological study of the effect of chronic $\stackrel{\overrightarrow{\vec{D}}}{\vec{D}}$ hypoxia and subsequent recovery of the heart and pul- $\tau$ monary vasculature of the rat. Cardiovasc Res 1971; $5: 95-102$.

9 Heath D, Edwards C, Winson M, Smith P. Effects on the right ventricle, pulmonary vasculature, and carotid $\square$ bodies of the rat of exposure to, and recovery from, D simulated high altitude. Thorax 1973;28:24-8.

10 Heath D, Williams DR. Man at high altitude. Edinburgh: $\vec{\circ}$ Churchill Livingstone, 1977. 